
Cipango
Cahiers d'études japonaises
$16 \mid 2009$
L'invention des « arts populaires » - Yanagi Sōetsu et le Mingei

\title{
Petit point d'ancrage par grand frais
}

\section{Michael Lucken}

\section{(2) OpenEdition \\ 1 Journals}

Édition électronique

URL : https://journals.openedition.org/cipango/187

DOI : $10.4000 /$ cipango. 187

ISSN : 2260-7706

Éditeur

INALCO

Édition imprimée

Date de publication : 1 janvier 2009

Pagination : 7-8

ISSN : 1164-5857

\section{Référence électronique}

Michael Lucken, «Petit point d'ancrage par grand frais », Cipango [En ligne], 16 | 2009, document 1, mis en ligne le 15 novembre 2011, consulté le 16 mars 2022. URL : http://journals.openedition.org/ cipango/187 ; DOI : https://doi.org/10.4000/cipango.187

Ce document a été généré automatiquement le 16 mars 2022.

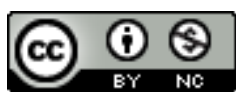

Cipango est mis à disposition selon les termes de la Licence Creative Commons Attribution - Pas d'Utilisation Commerciale 4.0 International. 


\title{
Petit point d'ancrage par grand frais
}

\author{
Michael Lucken
}

1 Le premier numéro de Cipango est sorti en janvier 1992. Si l'on prend en compte le temps qu'il fallut pour fédérer les énergies autour d'un projet incertain - une «tentative » disait Jean-Jacques Origas dans l'éditorial $\mathrm{du}^{\circ} \mathrm{n}^{\circ} 1$ - et les mois de travail pour rédiger et mettre en forme les premiers articles, voici quasiment vingt ans que notre revue existe. Un repère chronologique pour commencer, rond comme il se doit, comme fragile point d'ancrage.

2 Cipango a été lancée alors qu'il n'existait aucune revue en français spécialisée dans le domaine des études japonaises. Ce n'est que quelques mois plus tard, au printemps 1993, qu'Ebisu, sous l'impulsion d'Olivier Ansart, fut à son tour fondée. Avec ces deux revues, les chercheurs et notamment les plus jeunes se sont vu offrir des possibilités de publication qui peuvent sembler aujourd'hui évidentes à certains. Pourtant il n'y a aucune évidence à l'existence de nos revues dont chaque numéro ne doit sa parution qu'à la conjonction du hasard et de l'entêtement, nonobstant les découragements individuels, la malchance technique et les vents contraires de la haute politique. Il en va actuellement comme hier.

3 À l'origine, Cipango s'est appuyée sur ce qui était encore le tout petit vivier des chercheurs du Centre d'Études Japonaises de l'Inalco. Elle fut pilotée par un comité de rédaction qui comprenait Ninomiya Masayuki, Pierre Souyri, Dominique Giroux, François Macé, Jean-Jacques Origas et Gérard Martzel. Pascal Griolet rejoignit l'équipe à compter du $\mathrm{n}^{\circ} 2$, Emmanuel Lozerand à compter du n 3 . Toutefois, à partir de 1995, la revue chercha à s'ouvrir à des personnalités extérieures à l'INALCO, comme Patrick Beillevaire, Annick Horiuchi, Anne Bouchy ou Éric Seizelet. Ce travail d'ouverture a été poursuivi par Emmanuel Lozerand et moi-même qui, en tant que secrétaires de rédaction, avons respectivement animé la revue de 1997 à 2002 et de 2002 à 2009 . La formule qu'inaugure ce $n^{\circ} 16$ avec à la tête de la revue un binôme composé de JeanMichel Butel et Laurent Nespoulous affirme l'importance de Cipango dans le cadre français et plus largement francophone des études japonaises.

La polémique récente autour de la critique par Arnaud Nanta du livre de Jean-Louis Margolin, L'Armée de l'empereur, a donné à la revue un soudain éclairage médiatique 
auquel elle n'est pas habituée. Ce n'est pas sa vocation. En revanche, il est important de faire mieux connaître nos travaux à nos collègues qui travaillent dans des domaines connexes de l'histoire, de la littérature ou de la sociologie. Afin qu'à travers nos articles, l'on comprenne que ce qui, sur le plan théorique ou méthodologique, est nécessaire lorsqu'on parle de l'Allemagne ou de la France l'est aussi quand on aborde les cultures asiatiques. Pour être un historien du Japon, il faut être historien et japonologue, tout comme pour être historien de la Grèce antique, il faut être historien et connaître le grec ancien. Apprendre les langues des pays dont on prétend parler, c'est faire un effort vers l'autre, c'est courber l'échine et se sentir parfois incertain : c'est autant une exigence scientifique que morale.

\section{AUTEUR}

\section{MICHAEL LUCKEN}

Secrétaire de rédaction de la revue de 2002 à 2009. 